\title{
Nghiên cứu KHXH vì sự toàn vẹn lãnh thổ Việt Nam
}

\author{
Hồ Mạnh Toàn \\ Trung tâm ISR, Phenikaa University \\ Yên Nghĩa, Hà Đông, Hà Nội 100803, Việt Nam
}

Ngày 30 tháng 7 năm 2021

https://isr.phenikaa-uni.edu.vn/vi/post/tin-tuc/tin-tuc/sub-tin-tuc/nghien-cuu-khxh-vi-sutoan-ven-lanh-tho-viet-nam

ISR Phenikaa (Hồ Mạnh Toàn; ngày 30 tháng 7 năm 2021) - Ngày 29-7-2021, các báo lớn trong nước cũng như quốc tế đồng loạt đăng tải tin tức về chuyến thăm chính của Bộ trưởng Quốc phòng Hoa Kỳ Lloyd Austin tại Việt Nam, theo lời mời của Đại tướng Bộ trưởng Quốc phòng Việt Nam, Phan Văn Giang [1].

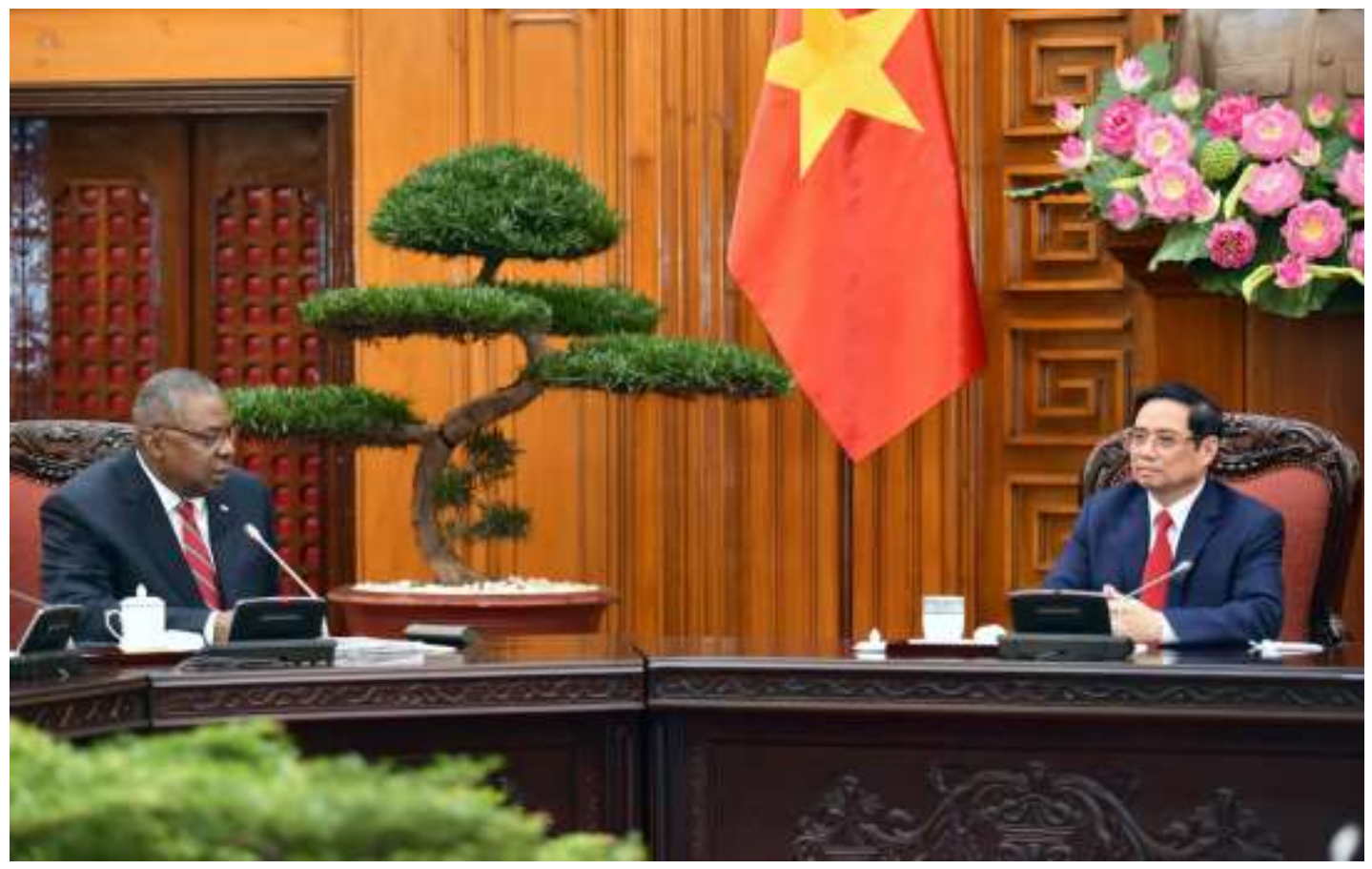

Thủ tướng Phạm Minh Chính nhấn mạnh các nội dung hợp tác về thúc đẩy thương mại, đâu tư, quốc phòng, hổ trợ nghiên cứu, chuyển giao công nghệ sản xuất vaccine COVID-19; hỗ trợ nhân đạo cho người dân bị ảnh hưởng bởi chất độc da cam/dioxin... Ảnh: VGP/Nhật Bắc

Chuyến thăm cấp cao của ông Austin đánh dấu bước phát triển về quan hệ hữu nghị giữa hai nước, đồng thời tiếp tục khẳng định các cam kết hợp tác chiến lược với nhiều 
nội dung quan trọng từ cuộc chiến chống COVID-19, sản xuất vaccine, hòa bình thịnh vượng khu vực ASEAN, nội dung về chính sách tiền tệ, vấn đề MIA,... [2].

Các nhà lãnh đạo của Việt Nam, Chủ tịch nước Nguyễn Xuân Phúc và Thủ tướng Phạm Minh Chính đã đón tiếp trọng thị ông Austin tại Hà Nội [2-3]. Theo thông tin Báo điện tử Chính phủ, một nội dung không tách rời là vấn đề hòa bình ở Biển Đông. Bài báo có đoạn kết như sau:

"Hai bên cũng thảo luận một số vấn đề khu vực và quốc tế cùng quan tâm, trong đó có tầm quan trọng của việc bảo đảm hòa bình, tự do, an ninh, an toàn hàng hải và hàng không ở Biển Đông, giải quyết các tranh chấp bằng biện pháp hòa bình trên cơ sở luật pháp quốc tế, trong đó có Công ước Liên Hợp Quốc về Luật Biển UNCLOS 1982, góp phần duy trì hòa bình, ổn định, hợp tác và phát triển trong khu vực và trên thế giới." [2]

Trong nhiều nội dung quan trọng của các hội đàm cấp nhà nước giữa lãnh đạo Việt Nam và Bộ trưởng Austin, quan hệ ngoại giao-chính trị-quân sự khu vực Đông Bắc và Đông Nam Á, là một trong những chủ đề nghiên cứu dài hơi của Trung tâm ISR (Đại học Phenikaa), với phương châm mục tiêu nghiên cứu KHXH\&NV cần đóng góp phụng sự toàn vẹn lãnh thổ tổ quốc.

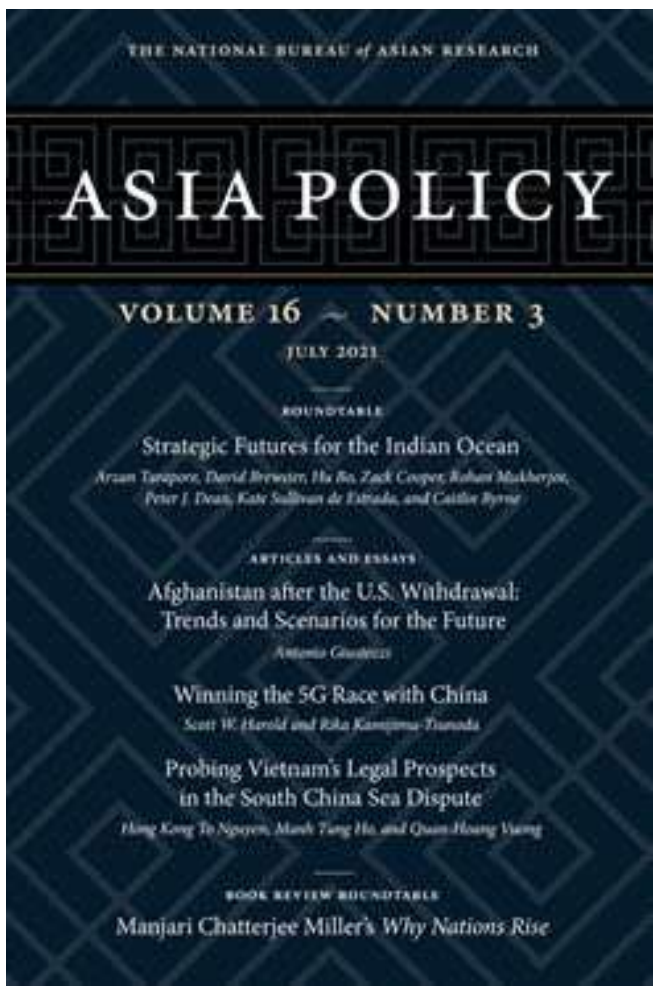

\section{Trang bìa tập san Asia Policy}

Cùng ngày 29-7, các cán bộ nghiên cứu của Trung tâm ISR cũng đã có bài báo nghiên cứu được xuất bản trên tập san Asia Policy, một ấn phẩm quan trọng xuất bản định kỳ 
của cơ quan nghiên cứu chiến lược Châu Á có trụ sở tại Washington D.C., The National Bureau of Asian Research (NBR). NBR cung cấp các phân tích chiến lược cho chính giới Hoa Kỳ trong quá trình hình thành chính sách ngoại giao-chính trị liên quan tới Châu Á.

Bài nghiên cứu cũng tập trung vào chủ đề Công ước Biển UNCLOS 1982 mà Bộ trưởng Quốc phòng Hoa Kỳ Lloyd Austin trao đổi với Đại tướng Bộ trưởng Quốc phòng Phan Văn Giang và Thủ tướng Phạm Minh Chính [1,3].

Nghiên cứu vừa xuất bản có tiêu đề "Probing Vietnam's Legal Prospects in the South China Sea Dispute", tập trung vào phân tích các quy tắc luật pháp quốc tế Việt Nam có khả năng sử dụng và thực thi, dựa trên hai trường hợp điển hình (Trung QuốcPhilippines và Úc-Timor Leste)về tranh chấp pháp lý trên biển sử dụng phương tiện phân xử hay hòa giải, cũng như các điều kiện thực thi [4].

Cách đây 2 năm, Trung tâm ISR cũng xuất bản một nghiên cứu [4] trên tập san quốc tế về chính trị-ngoại giao và phát triển kinh tế xã hội Đông Á, European Journal of East Asian Studies, là ấn phẩm hợp tác giữa một số trường đại học Châu Âu, do nhà xuất bản cổ kính Brill (thành lập từ năm 1683, xuất xứ từ Leiden, Hà Lan) phát hành. Nghiên cứu [5] phân tích quan hệ tương thuộc chính trị-kinh tế-xã hội giữa Việt Nam và Trung Quốc, xoay quanh trục vấn đề về niềm tin, yếu tố quyết định thành bại của các nỗ lực ngoại giao và hợp tác song phương Việt Nam-Trung Quốc.

Trong nỗ lực tăng cường chất lượng nghiên cứu, và năng lực tư vấn chính sách, Trung tâm ISR tiếp tục triển khai các nghiên cứu tầm toàn cầu, và sắp tới đây, cuốn monograph [6] sẽ xuất bản tại De Gruyter / Sciendo sẽ đánh dấu một bước tiến mới vào địa hạt nghiên cứu địa chính trị quốc tế, dựa trên phương pháp luận nghiên cứu đặc hữu do Trung tâm phát triển và thực hành qua nhiều năm.

\section{References:}

[1] Vũ Hùng. (2021). Bộ trưởng Quốc phòng Hoa Kỳ thăm chính thức Việt Nam. Quân Đội Nhân Dân (ngày 29 tháng 7). https://www.qdnd.vn/chinh-tri/tin-tuc/botruong-quoc-phong-hoa-ky-tham-chinh-thuc-viet-nam-666844

[2] TTXVN. (2021). Chủ tịch nước Nguyễn Xuân Phúc tiếp Bộ trưởng Quốc phòng Hoa Kỳ. Tuổi Trẻ (ngày 29 tháng 7). https://tuoitre.vn/chu-tich-nuoc-nguyen-xuanphuc-tiep-bo-truong-quoc-phong-hoa-ky-20210729142448345.htm

[3] Hà Văn. (2021). Thủ tướng Phạm Minh Chính tiếp Bộ trưởng Quốc phòng Hoa Kỳ. Báo điện tử Chính phủ (ngày 29 tháng 7). http://baochinhphu.vn/Hoat-dongcua-lanh-dao-Dang-Nha-nuoc/Thu-tuong-Pham-Minh-Chinh-tiep-Bo-truong-Quocphong-Hoa-Ky/440466.vgp

[4] Nguyen HKT, Ho MT, Vuong QH. (2021). Probing Vietnam's Legal Prospects in the South China Sea Dispute. Asia Policy, 16(3), 105-132. 
[5] Vuong QH, Vuong TT, Ho MT, Nguyen HKT. (2019). The 'same bed, different dreams' of Vietnam and China: how (mis)trust could make or break it. European Journal of East Asian Studies, 18(1), 93-128.

[6] Vuong QH, Nguyen MH, Le TT. (2021). A mindsponge-based investigation into the psycho-religious mechanism behind suicide attacks. Warsaw, Poland: De Gruyter / Sciendo (ISBN: 9788366675582). https://doi.org/10.2478/9788366675599 